\title{
Duration-controlled swimming exercise training induces cardiac hypertrophy in mice
}

\section{F.S. Evangelista ${ }^{1}$, P.C. Brum² and J.E. Krieger ${ }^{1}$}

\author{
${ }^{1}$ Instituto do Coração, Faculdade de Medicina, and \\ 2Escola de Educação Física e Esportes, Universidade de São Paulo, \\ São Paulo, SP, Brasil
}

\section{Correspondence \\ J.E. Krieger \\ Laboratório de Genética e \\ Cardiologia Molecular, InCor \\ Av. Dr. Enéas C. Aguiar, 44 \\ Bloco B, $10^{\circ}$ andar \\ 05403-000 São Paulo, SP \\ Brasil \\ Fax: +55-11-3069-5022 \\ E-mail: krieger@incor.usp.br \\ Research supported by FAPESP (No. 01/00009-0) and CNPq (No. 471219/01-0). F.S. Evangelista is the recipient of a doctoral fellowship from FAPESP (No. 99/01881-1).}

Received February 21, 2003 Accepted October 21, 2003

\begin{abstract}
Exercise training associated with robust conditioning can be useful for the study of molecular mechanisms underlying exercise-induced cardiac hypertrophy. A swimming apparatus is described to control training regimens in terms of duration, load, and frequency of exercise. Mice were submitted to 60- vs 90-min session/day, once $v s$ twice a day, with 2 or $4 \%$ of the weight of the mouse or no workload attached to the tail, for 4 vs 6 weeks of exercise training. Blood pressure was unchanged in all groups while resting heart rate decreased in the trained groups $(8-18 \%)$. Skeletal muscle citrate synthase activity, measured spectrophotometrically, increased (45-58\%) only as a result of duration and frequency-controlled exercise training, indicating that endurance conditioning was obtained. In groups which received duration and endurance conditioning, cardiac weight (14-25\%) and myocyte dimension (13-20\%) increased. The best conditioning protocol to promote physiological hypertrophy, our primary goal in the present study, was $90 \mathrm{~min}$, twice a day, 5 days a week for 4 weeks with no overload attached to the body. Thus, duration- and frequency-controlled exercise training in mice induces a significant conditioning response qualitatively similar to that observed in humans.
\end{abstract}

Key words - Exercise training

- Swimming

- Cardiac hypertrophy

- Mice

- Myocardium

\section{Introduction}

In response to a variety of mechanical, hemodynamic, hormonal and pathologic stimuli, the myocardium adapts to increased workloads through the hypertrophy of individual muscle cells (1). Cardiac hypertrophy can occur as an adaptive response to a physiological (exercise training) or pathological (valvular disease, hypertension, or obesity) increase in cardiac work (2,3). Different forms of cardiac hypertrophy arise as a result of a combination of genetic, physiologic, and environmental factors. The molecular mechanisms underlying exercise-induced physiological as well as pathological hypertrophy are poorly understood. In either concentric or eccentric pathological hypertrophy, the expression of cardiac embryonic genes such as those coding for natriuretic peptides is increased (4), but is unchanged in exercise-induced physiological hypertrophy (5). With the recent advances in transgenic and gene-targeting approaches, engineered mice have been used as a powerful tool to identify and validate genes and cellular pathways underlying different cardiovascular phenotypes such as hypertrophic (6) and di- 
lated (7) cardiomyopathies, but the lack of standardized and reproducible exercise training protocols has limited the understanding of this complex biological process.

Exercise training leads to improvement of cardiovascular capacity which is associated with lower resting and submaximal heart rates, increased ventricular weights and volume, and myocyte hypertrophy $(8,9)$. The adaptation to exercise training is dependent on factors such as training load, duration and frequency. Swimming is recognized for its efficiency in inducing myocardial hypertrophy and a significant increase in left ventricular end-diastolic volume in rats $(10,11)$. In the present study, we developed a robust and reproducible exercise training protocol for the development of cardiac hypertrophy in mice. A swimming training apparatus was built and used to test different swimming programs regarding duration, frequency and load of physical exercise. Using this approach, we provided evidence that duration and frequency but not load-controlled swimming training regimens lead to significant endurance conditioning and myocardial hypertrophy in mice.

\section{Material and Methods}

\section{Study population}

Nine-week-old male C57/BL6 mice ( $\mathrm{N}=$ 62) were maintained in a light- (12-h light

Table 1. Summary of swimming exercise training schedules used in the present study

\begin{tabular}{|c|c|c|c|c|c|c|}
\hline Protocol & $\begin{array}{l}\text { Training } \\
\text { group }\end{array}$ & $N$ & $\begin{array}{l}\text { Volume } \\
\text { (min) }\end{array}$ & $\begin{array}{l}\text { Intensity } \\
\text { (\% bw) }\end{array}$ & $\begin{array}{c}\text { Frequency } \\
\text { (sessions/day) }\end{array}$ & $\begin{array}{r}\text { Duration } \\
\text { (weeks) }\end{array}$ \\
\hline \multirow[t]{5}{*}{1} & $\mathrm{~T} 1$ & 6 & 90 & 0 & 2 & 6 \\
\hline & T2 & 5 & 60 & 0 & 2 & 6 \\
\hline & T3 & 6 & 90 & 0 & 1 & 6 \\
\hline & T4 & 5 & 60 & 2 & 2 & 6 \\
\hline & T5 & 7 & 60 & 4 & 2 & 6 \\
\hline \multirow[t]{2}{*}{2} & T6 & 7 & 90 & 0 & 2 & 4 \\
\hline & $\mathrm{T7}$ & 7 & 90 & 0 & 2 & 6 \\
\hline
\end{tabular}

$\mathrm{N}=$ number of mice; $\mathrm{bw}=$ body weight; volume = duration of each session training in minutes. cycle) and temperature- $\left(22^{\circ} \mathrm{C}\right)$ controlled environment and were fed a pellet rodent diet (Nuvital Nutrientes S/A, Curitiba, PR, Brazil) ad libitum and had free access to water. The training sessions were performed during the dark cycle of the mice which in the present study were kept from 7:00 to 19:00 h. The animals were randomly assigned to 3 sedentary $(\mathrm{S} 1-\mathrm{S} 3, \mathrm{~N}=19)$ and 7 exercise-trained (T1-T7, N = 43) groups according to the two protocols described below.

All animal experimental procedures followed Institutional guidelines and were approved by the Ethics Committee of the University of São Paulo Medical School.

\section{Training protocols}

Group assignment and number of mice used in each protocol are given in Table 1.

Protocol 1. The adaptation to exercise training depends on factors such as training load, duration and frequency. In protocol 1, duration, frequency and load of physical exercise were investigated. Training duration was associated with changes in length of exercise sessions (60 vs $90 \mathrm{~min}$ ), while exercise with the addition of different workloads ( 2 or $4 \%$ of body weight) modified the training load. Training frequency was investigated by comparing the number of exercise training sessions per day (once $v s$ twice a day). The aim was to optimize these parameters to induce robust cardiovascular effects, such as resting bradycardia and cardiac hypertrophy. The mice were randomly assigned to a sedentary $(\mathrm{S} 1, \mathrm{~N}=13)$ and five trained (T1-5, $\mathrm{N}=29$ ) groups. The $\mathrm{T} 1, \mathrm{~T} 2$ and $\mathrm{T} 3$ groups were exercised at the same load but with different duration or frequency of exercise, with $\mathrm{T} 1$ and $\mathrm{T} 2$ being used as duration groups and $\mathrm{T} 3$ as the frequency group. In contrast, T4 and T5 groups (load groups) were trained with the same duration and frequency of exercise but with different loads. 
The T1 group trained 5 days a week, twice a day with a gradual progression toward a 90-min session for 6 weeks. The T2 and $\mathrm{T} 3$ groups performed a swimming training protocol similar to that of the $\mathrm{T} 1$ group, except that exercise sessions were shorter (a 60-min session, twice a day). The training frequency of the $\mathrm{T} 2$ and $\mathrm{T} 3$ groups was also reduced (once a day, 90-min session). The T4 and T5 groups performed a swimming protocol similar to that of the T2 group (a 60min session), except that they were submitted to swimming with a 2 or $4 \%$ body weight workload, respectively. All mice were weighed once a week and when necessary the workload ( 2 or $4 \%$ of body weight) was adjusted to body weight changes. Sedentary mice were placed in the swimming apparatus for 5 min twice a week to mimic the water stress associated with the experimental protocol.

Protocol 2. In this protocol the results obtained for group $\mathrm{T} 1$ were evaluated with regard to the duration (4 vs 6 weeks) of training. Mice were randomly assigned to 2 sedentary (S2 and S3, 4 vs 6 weeks, respectively, $\mathrm{N}=6$ ) and 2 exercise-trained (T6 and T7, 4 vs 6 weeks, respectively, $\mathrm{N}=14$ ) groups.

\section{Swimming apparatus}

We designed a swimming apparatus especially planned for exercise training of mice. The system consists of two coupled 200-1 water glass tanks of different dimensions. The outer tank measures $60 \mathrm{~cm}$ in diameter, $100 \mathrm{~cm}$ in width and $50 \mathrm{~cm}$ in height. The inner tank is divided into 14 lanes with a surface area of $15 \times 15 \mathrm{~cm}$ per lane and a depth of $35 \mathrm{~cm}$ to allow individual training. To prevent floating during the swimming session, water bubbling was produced by tubes connected to an air pump system. A heating system kept the water temperature between 30 and $32^{\circ} \mathrm{C}$ and a water filter with a flow capacity of $420 \mathrm{l} / \mathrm{h}$ was used to clean the swimming apparatus (Figure 1).

\section{Resting systolic blood pressure and heart rate measurements}

Tail-cuff systolic blood pressure and heart rate (HR) were determined during the 4- or 6-week-period of study using a computerized tail-cuff system (BP 2000 Visitech Systems, Apex, NC, USA) (12). Blood pressure values were determined for each animal by averaging blood pressure measurements obtained on two different days of the same week during the animal's dark cycle.

\section{Analysis of cardiac structure}

Twenty-four hours after the last exercise training session, sedentary and exercisetrained mice were killed and tissues harvested. The weights of the heart and of the dissected chamber atria, right ventricle and left ventricle were measured. The dissected chambers were then fixed by immersion in $4 \%$ buffered formalin and embedded in paraffin for routine histologic processing. Sections $(4 \mu \mathrm{m})$ were stained with hematoxylin and eosin for examination with a light microscope. Myocyte width was measured in the left ventricle free wall with a computer-



Figure 1. Swimming apparatus for mouse physical training. 
assisted morphometric system (Leica Quantimet 500, Cambridge, UK). For 10 myocytes containing a nucleus visible in the field, a single transverse measurement of width passing through the nucleus was determined. Myocyte diameter was determined for each animal by averaging the measured myocytes.

\section{Skeletal muscle oxidative enzyme activity}

Muscle samples were taken from the left and right soleus at the time of killing and frozen in liquid nitrogen for later processing. Citrate synthase activity was measured spectrophotometrically in whole muscle homogenates and the amount of the complex resulting from coenzyme A and oxaloacetate was determined (13).

\section{Statistical analysis}

Data are reported as means \pm SEM. Data for the exercise-trained groups were compared to those for the sedentary groups using oneway ANOVA for repeated measures and twoway ANOVA followed by the Tukey post hoc test in Protocols 1 and 2, respectively. Statistical significance was set at $\mathrm{P} \leq 0.05$.

\section{Results}

\section{Resting systolic blood pressure and heart rate during the exercise-training period}

Baseline blood pressure did not differ among the groups studied in Protocol 1 (Figure $2 \mathrm{~A}$ ). In contrast, after 3 weeks of exercise training, HR decreased significantly in all trained groups compared to the pre-exercise period (T1, 12.3\%; T2, 12\%; T3, 8.3\%; $\mathrm{T} 4,10 \%$, and $\mathrm{T} 5,8 \%$ ) as well as to sedentary littermates (Figure 2B). In contrast, HR was unchanged in the sedentary group throughout the study. The development of resting bradycardia in the exercising mice indicates that aerobic conditioning was achieved with these training regimens (14).

In Protocol 2, reduction of exercise training from 6 to 4 weeks resulted in no change in blood pressure or HR responses (Figure $2 \mathrm{C}$ and $\mathrm{D}$, respectively). Baseline blood pressure remained unchanged in all sedentary and exercise-trained groups, while signifi-
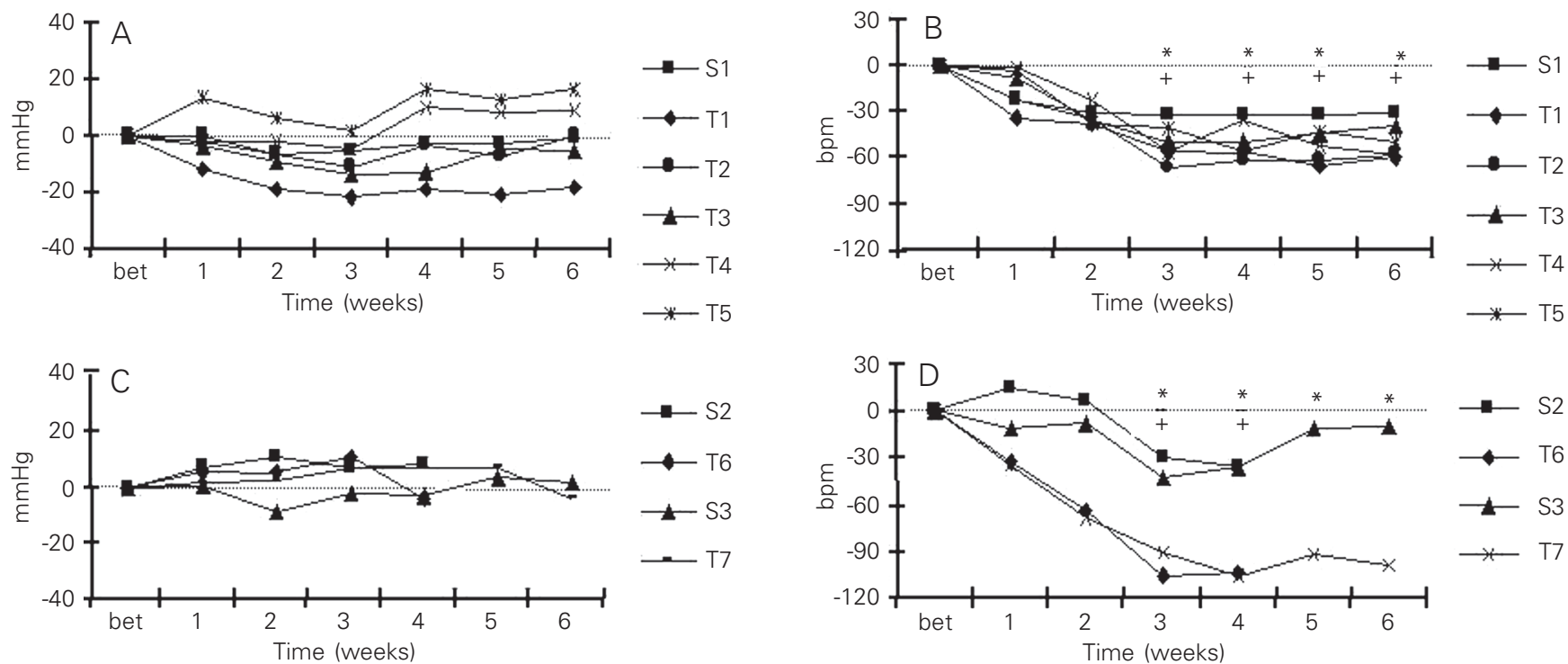

Figure 2. Resting systolic blood pressure $(\mathrm{mmHg})$ and heart rate $(\mathrm{bpm})$ during physical training in Protocols $1(\mathrm{~A}$ and $\mathrm{B})$ and $2(\mathrm{C}$ and $\mathrm{D})$. Data are reported as mean \pm SEM. ${ }^{*} P<0.05$ compared to the sedentary groups $S 1$ (B) and S2 and S3 (D) at the same time. ${ }^{+P}<0.05$ compared to the trained groups before and after physical training (two-way ANOVA test). Resting blood pressure did not change among groups after physical training; however, heart rate decreased in all trained groups after 2-3 weeks of physical training $(P<0.05)$. bet = before exercise training. 
cant resting bradycardia was achieved at both T6 (18\%) and T7 (16.4\%) 4 and 6 weeks of exercise training, respectively, compared to sedentary littermates (Figure 2D).

\section{Cardiac structure analysis}

The body weights of exercise-trained mice from the T1 to T4 groups were similar to those of sedentary mice (Table 2). In contrast, mice exercised at a higher load (T5) showed a significantly lower body weight than sedentary mice. In Protocol 2, the body weight of T6 mice did not differ from that of their sedentary littermates, while $\mathrm{T} 7$ mice had a significantly lower body weight than S3.

Cardiac hypertrophy was observed only in mice from duration (T1) and load groups (T4 and T5) in Protocol 1 (Table 2). The increased heart weight to body weight ratio was mainly due to an increase in left ventricle weight in the $\mathrm{T} 1$ and $\mathrm{T} 4$ groups. In the load group (T4), the normalized weight of the atria also contributed to the increased heart weight. In contrast, in the group exercised at a higher load (T5) the normalized increase in heart weight was associated mainly with a smaller body weight.

The magnitude of cardiac hypertrophy was not influenced by reduction of exercise training from 6 to 4 weeks. Both the T6 and T7 groups presented increased heart weight to body weight ratios mainly due to an increased left ventricle weight to body weight ratio (Table 2 ).

Changes in myocyte width paralleled the changes observed in the left ventricle to body weight ratios. A significant increase in myocyte width was observed in the exercisetrained groups (T1, T4, T6 and T7) compared to sedentary littermates in both protocols (Figure 3A,C).

\section{Skeletal muscle oxidative enzyme activity}

An increased muscle oxidative activity concomitant with an increase in aerobic work capacity is one of the hallmarks of skeletal muscle adaptation to aerobic conditioning. We measured the maximal activity of citrate synthase (an enzyme involved in the citric acid cycle) in the soleus muscle of all exercise-trained and sedentary mice as a marker of muscle oxidative activity.

Interestingly, in Protocol 1, the maximal activity of citrate synthase was significantly

Table 2. Cardiac morphometric analysis following physical training in Protocols 1 and 2.

\begin{tabular}{cccllll}
\hline Protocol & Group & BW $(\mathrm{g})$ & $\mathrm{H} / \mathrm{BW}(\mathrm{mg} / \mathrm{g})$ & LV/BW $(\mathrm{mg} / \mathrm{g})$ & $\mathrm{RV} / \mathrm{BW}(\mathrm{mg} / \mathrm{g})$ & AT/BW $(\mathrm{mg} / \mathrm{g})$ \\
\hline 1 & S1 & $25.5 \pm 0.50$ & $4.02 \pm 0.07$ & $3.04 \pm 0.06$ & $0.78 \pm 0.02$ & $0.19 \pm 0.01$ \\
& T1 & $23.0 \pm 0.66$ & $4.51 \pm 0.00^{*}$ & $3.47 \pm 0.07^{*}$ & $0.82 \pm 0.03$ & $0.23 \pm 0.01$ \\
& T2 & $23.4 \pm 0.12$ & $4.35 \pm 0.09$ & $3.32 \pm 0.07$ & $0.82 \pm 0.03$ & $0.23 \pm 0.01$ \\
& T3 & $24.7 \pm 0.94$ & $4.20 \pm 0.20$ & $3.21 \pm 0.17$ & $0.78 \pm 0.04$ & $0.21 \pm 0.01$ \\
& T4 & $23.6 \pm 0.44$ & $4.62 \pm 0.19^{*}$ & $3.48 \pm 0.14^{*}$ & $0.87 \pm 0.05$ & $0.27 \pm 0.01^{*}$ \\
& T5 & $22.7 \pm 0.60^{*}$ & $4.50 \pm 0.09^{*}$ & $3.34 \pm 0.07$ & $0.89 \pm 0.04$ & $0.28 \pm 0.01^{*}$ \\
& & & & & & \\
& S2 & $23.17 \pm 0.80$ & $3.94 \pm 0.10$ & $2.92 \pm 0.03$ & $0.80 \pm 0.03$ & $0.22 \pm 0.01$ \\
& S3 & $25.90 \pm 0.85$ & $4.21 \pm 0.01$ & $3.09 \pm 0.04$ & $0.90 \pm 0.07$ & $0.22 \pm 0.01$ \\
& T6 & $21.34 \pm 0.46$ & $4.93 \pm 0.04^{* *}$ & $3.67 \pm 0.04^{* *}$ & $0.93 \pm 0.01$ & $0.34 \pm 0.01^{*}$ \\
& T7 & $22.20 \pm 0.82^{+}$ & $5.13 \pm 0.13^{*}$ & $3.80 \pm 0.10^{+}$ & $1.01 \pm 0.04$ & $0.29 \pm 0.02$
\end{tabular}

$\mathrm{AT}=$ atria, $\mathrm{BW}=$ body weight, $\mathrm{H}=$ heart, $\mathrm{LV}=$ left ventricle, $\mathrm{RV}=$ right ventricle, $\mathrm{S}=$ sedentary group, $\mathrm{T}=$ training group. Data are reported as mean \pm SEM .

${ }^{*} \mathrm{P}<0.05$ compared to $\mathrm{S} 1,{ }^{*} \mathrm{P}<0.05$ compared to $\mathrm{S} 2$, and $+\mathrm{P}<0.05$ compared to S3 (two-way ANOVA test). As shown, cardiac hypertrophy was significant in groups T1, T4, T5, T6 and T7 due mainly to an increase in left ventricular and atrial weight. 
higher only in exercise-trained mice from the duration group when compared with sedentary mice and other trained groups (Figure 3B). In Protocol 2, exercise-trained mice from the T6 and T7 groups showed a significant increase in citrate synthase activity when compared to their respective sedentary littermates (Figure 3D).

\section{Discussion}

In the current study we examined exercise conditioning, which represents one of the major cardiovascular adaptations to chronic cardiovascular stress, and provide evidence that duration- and frequency-controlled but not load-controlled exercise training regimens induce substantial endurance conditioning and myocardial hypertrophy in mice. These results suggest that the duration- and frequency-controlled training regimens can be useful to unravel the role of particular genes and pathways in exerciseinduced cardiac hypertrophy in the context of the whole animal.

\section{Exercise training model}

Swimming rather than running was chosen as a model because of its efficiency in inducing myocardial hypertrophy and greater left ventricular end-diastolic volume in rats $(10,11)$. Although most treadmill running studies have failed to show cardiac hypertrophy in rats $(15,16)$, some investigators $(17,18)$ have observed cardiac hypertrophy in mice trained in voluntary running protocols or intensity-controlled treadmill running. However, it is important to emphasize that conditioning associated with voluntary running in wheels is difficult to quantify because there is a wide variation in the amount of running among animals. Even though Kemi et al. (17) recently showed that graded running intensity results in major increments of ventricular mass than fixed running intensity, their protocol was probably restricted to healthy mice considering the intensity levels achieved during the exercise training period (85-90\% $\left.\mathrm{VO}_{2 \max }\right)$. Regarding swimming, most training protocols $(3,19-21)$ have adopted group swimming, which promotes a vigorous response but adds stress as an important confounding variable. One exception is the study by Kaplan et al. (19) showing a swimming training-induced cardiac hypertrophy limited to female mice.

In the present study, we developed a swimming apparatus for mice with individual lanes and bubbling water to avoid animal floating, which facilitated the control of load, duration and frequency during the swim-
Figure 3. Left cardiac myocyte dimensions and skeletal muscle maximal citrate synthase activity following physical training in Protocols 1 ( $\mathrm{A}$ and $\mathrm{B}$ ) and 2 (C and D). Data are reported as means \pm SEM. ${ }^{*} P<0.05$ compared to the sedentary groups S1 ( $A$ and B; one-way ANOVA test) and $S$ (C and D; two-way ANOVA test).

Trained mice, $\mathrm{T} 1$ and $\mathrm{T} 4$ from Protocol 1 and T6 and T7 from Protocol 2, showed an increase in myocyte dimensions confirming the increase cardiac weight. However, citrate synthase activity was higher only in groups T1, T6 and T7.
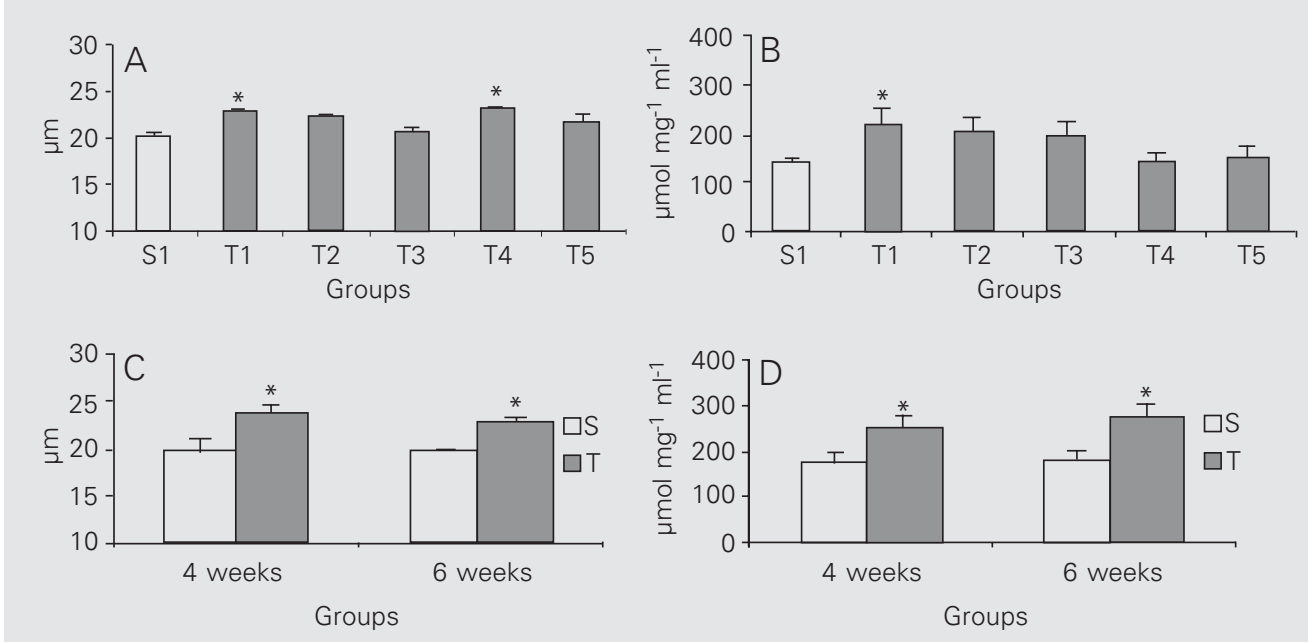
ming sessions. As previously described (19), minimal diving was observed in mice and their forelegs were relatively inactive during swimming, with almost all of the vigorous muscular activity being performed by the hindlegs.

The current study demonstrated that mice who are close to their limit of functional adaptation (very high peak oxygen uptake, intrinsic HR and cardiac sympathetic tone) develop cardiac hypertrophy and endurance conditioning by swimming.

\section{Blood pressure and heart rate responses}

Resting bradycardia is a useful and reliable indicator of endurance conditioning (22). The exercise-trained groups showed a lower resting HR when compared to the sedentary groups $(\mathrm{P}<0.05)$. However, the magnitude of resting bradycardia was higher in the duration-controlled trained groups (12-18\%) than in the load- and frequency-controlled trained groups (8-10\%). The bradycardic response occurred two to three weeks after training in all groups. Although the magnitude of resting bradycardia did not differ significantly among the trained groups, mice from the T6 and $\mathrm{T} 7$ groups (duration-controlled training regimen, Protocol 2) tended to present a greater magnitude of resting bradycardia than T1 mice (duration-controlled training regimen, Protocol 1). This response might be related to the variability of resting HR values in this species. In a recent review, Bernstein (23) pointed out the wide variability in the definition of normal resting HR in mice, with reported values ranging from 212 to $690 \mathrm{bpm}(24,25)$.

There was no difference in systolic blood pressure after all swimming training regimens when exercise-trained mice were compared with sedentary littermates. These results are consistent with previous observations by our group $(26,27)$ and others $(28)$ showing that arterial pressure remains unchanged in exercise-trained normotensive animals and humans.

\section{Skeletal muscle oxidative capacity}

The adaptation of skeletal muscle oxidative capacity induced by exercise training is well established and is also considered to be a good marker for exercise training efficiency (29). However, few swimming studies in rodents have documented an increased skeletal muscle oxidative capacity associated with exercise training (30). One of the purposes of the present study was to determine if skeletal muscle oxidative capacity would be affected by different swimming training regimens in mice. Interestingly, we observed a significant elevation in citrate synthase activity only in the duration-controlled exercise groups from Protocol 1 (T1, $58 \%$ ), and Protocol 2 (T6, 45\%, and T7, $54 \%$ ) groups. In contrast, the lower duration (T2), frequency (T3), and load groups (T4 and T5) showed no significant changes in citrate synthase activity. These results suggest that duration-controlled exercise training is the most efficient regimen for inducing skeletal muscle adaptation in mice. In fact, duration of training has been identified as the main factor affecting skeletal muscle oxidative capacity after exercise training in rodents (31). In contrast, the effect of load exercise training on oxidative enzyme activity in rodents remains controversial $(32,33)$.

\section{Ventricular weights and left ventricular cardiac myocyte dimensions}

Although an increase in heart weight-tobody weight ratio had been previously reported in mice $(19,34,35)$, the present data are the first to demonstrate that the increase in heart weight is influenced by exercise training regimens. We found that the duration-controlled swimming training was the most efficient regimen for inducing cardiac hypertrophy in mice. Other studies with different physical training protocols such as 
voluntary wheel running (18) and treadmill running (17) have reported smaller cardiac hypertrophies (10 and $12.3 \%$, respectively) compared to the present study (25\%). The hypertrophic responses were accompanied by an increase in myocyte width. Interestingly, the time course of exercise training (4 vs 6 weeks) did not influence the magnitude of cardiac hypertrophy (groups T6 vs T7).

\section{Limitations of the present study}

Swimming has been suggested to be the most efficient type of exercise for inducing conditioning and cardiac hypertrophy in animals (36) even though it is associated with an important stress response (28). We placed the mice from the sedentary groups in the water for 5 min twice a week in an attempt to minimize the effect of stress when comparing sedentary $v s$ trained groups. Furthermore, although the corticosterone levels were not assessed in these animals, the adrenal gland weight was determined and did not differ among groups (data not shown).

Earlier studies have demonstrated that exercise training by swimming increases the heart weight-to-body weight ratio by 12 to $31 \%$ in rats (16) and by 16 to $29 \%$ in mice
$(19,34)$. Cardiac hypertrophy is well known to occur in response to various stimuli, such as pressure and volume overload. Exercise training is mainly related to a volume overload-induced cardiac eccentric hypertrophy with predominant longitudinal myocyte growth (1). Although myocyte length has not been determined, we were able to detect an increase in myocyte width which paralleled the changes observed in left ventricle to body weight ratios. This is consistent with the idea that exercise training-induced eccentric hypertrophy can lead to proportional myocyte width and length growth (37).

In the present investigation, training regimens associating duration, load, and frequency of exercise were restricted to male mice. We cannot exclude a gender effect on this response although similar cardiovascular and metabolic responses to physical training have been shown in male and female rats (17).

In the present study we describe a swimming apparatus to produce exercise-induced cardiac hypertrophy in mice and provide evidence indicating that duration- and frequency-controlled but not load-controlled exercise is associated with physical conditioning in mice.

\section{References}

1. Lorell BH \& Carabello BA (2000). Left ventricular hypertrophy: pathogenesis, detection, and prognosis. Circulation, 102: 470-479.

2. Hunter JJ \& Chien KR (1999). Signaling pathways for cardiac hypertrophy and failure. New England Journal of Medicine, 341: 12761283.

3. Scheuer J, Malhotra A, Hirsch C, Capasso J \& Schaible TF (1982). Physiologic cardiac hypertrophy corrects contractile protein abnormalities associated with pathologic hypertrophy in rats. Journal of Clinical Investigation, 70: 1300-1305.

4. Bianciotti LG \& de Bold AJ (2002). Natriuretic peptide gene expression in DOCA-salt hypertension after blockade of type B endothelin receptor. American Journal of Physiology, 282: H1127-H1134.

5. lemitsu M, Miyauchi T, Maeda S, Sakai S, Kobayashi T, Fujii N, Miyazaki H, Matsuda M \& Yamaguchi I (2001). Physiological and pathological cardiac hypertrophy induce different molecular phenotypes in the rat. American Journal of Physiology, 281: R2029-R2036.

6. Aronow BJ, Toyokawa T, Cannin A, Haghighi K, Delling U, Kranias E, Molkentin JD \& Dorn GW (2001). Divergent transcriptional re- sponses to independent genetic causes of cardiac hypertrophy. Physiological Genomics, 6: 19-28.

7. Hardt SE, Geng YJ, Montagne O et al. (2002). Accelerated cardiomyopathy in mice with overexpression of cardiac G(s)alpha and a missense mutation in the alpha-myosin heavy chain. Circulation, 105: $614-620$.

8. Wisloff U, Helgerud J, Kemi OJ \& Ellingsen O (2001). Intensitycontrolled treadmill running in rats: $\mathrm{VO}(2 \mathrm{max})$ and cardiac hypertrophy. American Journal of Physiology, 280: H1301-H1310.

9. Yamamoto K, Miyachi M, Saitoh T, Yoshioka A \& Onodera S (2001). Effects of endurance training on resting and post-exercise cardiac autonomic control. Medicine and Science in Sports and Exercise, 33: 1496-1502.

10. Geenen D, Buttrick P \& Scheuer J (1988). Cardiovascular and hormonal responses to swimming and running in the rat. Journal of Applied Physiology, 65: 116-123.

11. Oscai LB, Mole PA, Brei B \& Holloszy JO (1971). Cardiac growth and respiratory enzyme levels in male rats subjected to a running 
program. American Journal of Physiology, 220: 1238-1241.

12. Krege JH, Hodgin JB, Hagaman JR \& Smithies O (1995). A noninvasive computerized tail-cuff system for measuring blood pressure in mice. Hypertension, 25: 1111-1115.

13. Srere PA (1969). Citrate synthase. In: Lowenstein JM (Editor), Methods in Enzymology. Academic Press, New York, USA.

14. Tipton CM (1965). Training and bradycardia in rats. American Journal of Physiology, 209: 1089-1094.

15. Fitzsimons DP, Bodell PW, Herrick RE \& Baldwin KM (1990). Left ventricular functional capacity in the endurance-trained rodent. Journal of Applied Physiology, 69: 305-312.

16. Schaible TF \& Scheuer J (1981). Cardiac function in hypertrophied hearts from chronically exercised female rats. Journal of Applied Physiology, 50: 1140-1145.

17. Kemi OJ, Loennechen JP, Wisloff U \& Ellingsen O (2002). Intensitycontrolled treadmill running in mice: cardiac and skeletal muscle hypertrophy. Journal of Applied Physiology, 93: 1301-1309.

18. Allen DL, Harrison BC, Maass A, Bell ML, Byrnes WC \& Leinwand LA (2001). Cardiac and skeletal muscle adaptations to voluntary wheel running in the mouse. Journal of Applied Physiology, 90: 1900-1908.

19. Kaplan ML, Cheslow Y, Vikstrom K, Malhotra A, Geenen DL, Nakouzi A, Leinwand LA \& Buttrick PM (1994). Cardiac adaptations to chronic exercise in mice. American Journal of Physiology, 267: H1167H1173.

20. Nakao C, Yamada E, Fukaya M, Tayama K, Tsukamoto $Y$ \& Sato $Y$ (2001). Effect of acetate on glycogen replenishment in liver and skeletal muscles after exhaustive swimming in rats. Scandinavian Journal of Medicine and Science in Sports, 11: 33-37.

21. Ueno N, Oh-ishi S, Kizaki T, Nishida M \& Ohno H (1997). Effects of swimming training on brown-adipose-tissue activity in obese ob/ob mice: GDP binding and UCP m-RNA expression. Research Communications in Molecular Pathology and Pharmacology, 95: 92-104.

22. Lewis $S$, Thompson $P$, Areskog NH, Vodak P, Marconyak M, DeBusk R, Mellen S \& Haskell W (1980). Transfer effects of endurance training to exercise with untrained limbs. European Journal of Applied Physiology and Occupational Physiology, 44: 25-34.

23. Bernstein D (2003). Exercise assessment of transgenic models of human cardiovascular disease. Physiological Genomics, 13: 217226.

24. Iwase M, Bishop SP, Uechi M et al. (1996). Adverse effects of chronic endogenous sympathetic drive induced by cardiac Gsa overexpression. Circulation Research, 78: 517-524.

25. Gardin JM, Siri FM, Kitsis RN, Edwards JG \& Leinwand LA (1995). Echocardiographic assessment of left ventricular mass and systolic function in mice. Circulation Research, 76: 907-914.

26. Krieger EM, Brum PC \& Negrão CE (1998). Role of arterial baroreceptor function on cardiovascular adjustments to acute and chronic dynamic exercise. Biological Research, 31: 273-279.

27. Negrão CE, Irigoyen MC, Moreira ED, Brum PC, Freire PM \& Krieger EM (1993). Effect of exercise training on RSNA, baroreflex control, and blood pressure responsiveness. American Journal of Physiology, 265: R365-R370.

28. Desai KH, Sato R, Schauble E, Barsh GS, Kobilka BK \& Bernstein D (1997). Cardiovascular indexes in the mouse at rest and with exercise: new tools to study models of cardiac disease. American Journal of Physiology, 272: H1053-H1061.

29. Wibom R, Hultman E, Johansson M, Matherei K, ConstantinTeodosiu D \& Schantz PG (1992). Adaptation of mitochondrial ATP production in human skeletal muscle to endurance training and detraining. Journal of Applied Physiology, 73: 2004-2010.

30. Pereira BCRLF, Safi DA, Medeiros MH, Curi R \& Bechara EJ (1994). Superoxide dismutase, catalase and glutathione peroxidase activities in muscle and lymphoid organs of sedentary and exercisetrained rats. Physiology and Behavior, 56: 1095-1099.

31. Benzi G, Panceri P, de Bernardi M, Villa R, Arcelli E, D’Angelo L, Arrigoni $E$ \& Berte $F$ (1975). Mitochondrial enzymatic adaptation of skeletal muscle to endurance training. Journal of Applied Physiology, 38: 565-569.

32. Dohm GL, Beecher GR, Stephenson TP \& Womack M (1977). Adaptations to endurance training at three intensities of exercise. Journal of Applied Physiology, 42: 753-757.

33. Gillespie AC, Fox EL \& Merola AJ (1982). Enzyme adaptations in rat skeletal muscle after two intensities of treadmill training. Medicine and Science in Sports and Exercise, 14: 461-466.

34. Rothermel BA, McKinsey TA, Veja RB et al. (2001). Myocyte-enriched calcineurin-interacting protein, MCIP1, inhibits cardiac hypertrophy in vivo. Proceedings of the National Academy of Sciences, USA, 98: 3328-3333.

35. Spencer FA, Meyer TE, Gore JM \& Goldberg RJ (2002). Heterogeneity in the management and outcomes of patients with acute myocardial infarction complicated by heart failure: the national registry of myocardial infarction. Circulation, 105: 2605-2610.

36. Schaible TF \& Scheuer J (1979). Effects of physical training by running or swimming on ventricular performance of rat hearts. Journal of Applied Physiology, 46: 854-860.

37. Claessens $C$, Claessens $P$, Bloemen $H$, Claessens $M$, Verbanck $M$, Fagard R \& Claessens J (1999). Structural heart adaptations in triathletes. Acta Cardiologica, 54: 317-325. 